\author{
RADOSŁAW KALETA \\ Uniwersytet Warszawski \\ Warszawa, Polska
}

\title{
О транслитерации и транскрипции белорусских слов
}

Один из белорусских исследователей (Кошчанка 2015: 177) в своей статье представил сорок один вариант передачи латинскими буквами названия белорусского города Могилёв (белор. Магілёў, польск. Mohylew), что показывает сложность вопроса транслитерации и транскрипции белорусских названий. Большое количество вариантов транслитерации связано также с тем, что в Республике Беларусь два государственных языка и поэтому фамилии граждан и географические названия могут транслитерироваться как с белорусского, так и русского языков. Кроме того, существуют варианты как транслитерации, так и транскрипции, которая, как правило, должна передавать звуки иностранного языка в форме похожей на произношение, действующее в данной стране. Поэтому французская транскрипция данного географического названия или фамилии будет отличаться от английской, немецкой или польской транскрипций. Каждая страна может иметь свой вариант транскрипции согласно отечественному произношению, в то время как транслитерация относится к письменной форме языка и заключается в передаче данного слова буквами другого алфавита. Существует много вариантов транслитерации белорусского алфавита. В этой статье будут обсуждаться главные из них.

В первую очередь стоит упомянуть о белорусской латинке (белорусском латинском алфавите), которая является основой новейшей белорусской транслитерации географических названий. В белорусской латинке есть буквы с польского алфавита (мягкие: $\dot{c}, \dot{n}, \dot{s}, \dot{z}$, и диграфы: $c h, d z, d z)$ и чешского алфавита (твёрдые: $\check{c}, \check{s}, \check{z}$ ). Диграф $d \dot{z}$ передается как $d \check{z}$.

Типичная белорусская буква $\check{y}$ называется «у краткое» («у неслоговое», на белорусском — «у нескладовае»). В белорусском латинском алфавите используется другой порядок букв, чем в кириллице. 
Белорусская латинка и её эквиваленты в кириллице

\begin{tabular}{|c|c|c|c|}
\hline Латинка & $\begin{array}{c}\text { Эквиваленты в кирил- } \\
\text { лице }\end{array}$ & $\begin{array}{c}\text { Порядок букв в бело- } \\
\text { русском кирилличном } \\
\text { алфавите }\end{array}$ & $\begin{array}{c}\text { Эквиваленты в белорус- } \\
\text { ской латинке }\end{array}$ \\
\hline A, a & A, a & A, a & $\mathrm{A}, \mathrm{a}$ \\
\hline $\mathrm{B}, \mathrm{b}$ & Б, б & Б, б & $\mathrm{B}, \mathrm{b}$ \\
\hline $\mathrm{C}, \mathrm{c}$ & Ц, ц & $\mathrm{B}, \mathrm{B}$ & V, v (раньше W, w) \\
\hline Ć, ć & ЦЬ, ць & $\Gamma, \Gamma$ & $\mathrm{H}, \mathrm{h}(\mathrm{G}, \mathrm{g})^{1}$ \\
\hline$\check{C}, \check{c}$ & Ч, ч & Д, д & $\mathrm{D}, \mathrm{d}$ \\
\hline $\mathrm{D}, \mathrm{d}$ & Д, д & Дж, дж & DŽ, dž (раньше Dż, dż) \\
\hline $\mathrm{DZ}, \mathrm{dz}$ & Д3, дз & Дз, дз & $\mathrm{DZ}, \mathrm{dz}$ \\
\hline DŹ, dź & ДЗЬ, дзь & E, e & $\begin{array}{c}\mathrm{Je}, \mathrm{je}^{2} \\
\mathrm{e}^{3} \\
\mathrm{ie}^{4}\end{array}$ \\
\hline $\mathrm{DŽ}, \mathrm{dž}$ & ДЖ, дж & Ë, ë & $\begin{array}{c}\mathrm{Jo}, \mathrm{jo}^{2} \\
\mathrm{o}^{3} \\
\mathrm{io}^{4} \\
\end{array}$ \\
\hline $\mathrm{F}, \mathrm{f}$ & $\Phi, \phi$ & Ж, ж & Ž, ž (раньше Ż, ̇̇) \\
\hline $\mathrm{G}, \mathrm{g}$ & I, г & 3,3 & $\mathrm{Z}, \mathrm{z}$ \\
\hline $\mathrm{H}, \mathrm{h}$ & $\Gamma, \Gamma$ & $\mathrm{I}, \mathrm{i}$ & $\mathrm{I}, \mathrm{i}$ \\
\hline $\mathrm{CH}$, ch & $\mathrm{X}, \mathrm{x}$ & Й, й & $\mathrm{J}, \mathrm{j}$ \\
\hline $\mathrm{I}, \mathrm{i}$ & $\mathrm{I}, \mathrm{i}$ & К, к & $\mathrm{K}, \mathrm{k}$ \\
\hline $\mathrm{J}, \mathrm{j}$ & Й, й & Л, л & $\begin{array}{l}\mathrm{L}, 1^{5} \\
\mathrm{~L}, 1\end{array}$ \\
\hline $\mathrm{K}, \mathrm{k}$ & К, к & M, м & $\mathrm{M}, \mathrm{m}$ \\
\hline $\mathrm{L}, 1$ & Ль, ль & $\mathrm{H}, \mathrm{H}$ & $\mathrm{N}, \mathrm{n}$ \\
\hline$€, 1$ & Л, л & $\mathrm{O}, \mathrm{o}$ & $\mathrm{O}, \mathrm{o}$ \\
\hline $\mathrm{M}, \mathrm{m}$ & M, м & П, п & $\mathrm{P}, \mathrm{p}$ \\
\hline $\mathrm{N}, \mathrm{n}$ & $\mathrm{H}, \mathrm{H}$ & $\mathrm{P}, \mathrm{p}$ & $\mathrm{R}, \mathrm{r}$ \\
\hline Ń, ń & НЬ, нь & $\mathrm{C}, \mathrm{c}$ & $\mathrm{S}, \mathrm{s}$ \\
\hline $\mathrm{O}, \mathrm{o}$ & $\mathrm{O}, \mathrm{o}$ & $\mathrm{T}, \mathrm{T}$ & $\mathrm{T}, \mathrm{t}$ \\
\hline $\mathrm{P}, \mathrm{p}$ & П, п & $\mathrm{y}, \mathrm{y}$ & $\mathrm{U}, \mathrm{u}$ \\
\hline $\mathrm{R}, \mathrm{r}$ & $\mathrm{P}, \mathrm{p}$ & $\breve{y}, \breve{y}$ & $\breve{\mathrm{U}}, \breve{\mathrm{u}}$ \\
\hline $\mathrm{S}, \mathrm{s}$ & $\mathrm{C}, \mathrm{c}$ & $\Phi, \phi$ & $\mathrm{F}, \mathrm{f}$ \\
\hline Ś, ś & СЬ, сь & $\mathrm{X}, \mathrm{x}$ & Ch, ch \\
\hline Š, š & Ш, ш & Ц, ц & $\mathrm{C}, \mathrm{c}$ \\
\hline $\mathrm{T}, \mathrm{t}$ & $\mathrm{T}, \mathrm{T}$ & Ч, ч & $\check{\mathrm{C}}$, с $($ раньше Cz, cz) \\
\hline $\mathrm{U}, \mathrm{u}$ & $\mathrm{y}, \mathrm{y}$ & Ш, ш & Š, š (раньше Sz, sz) \\
\hline$\breve{\mathrm{U}}, \breve{\mathrm{u}}$ & $\breve{y}, \breve{y}$ & Ы, ы & $\mathrm{Y}, \mathrm{y}$ \\
\hline
\end{tabular}




\begin{tabular}{|c|c|c|c|}
\hline $\mathrm{V}, \mathrm{v}$ & $\mathrm{B}$, в & b & 6 \\
\hline $\mathrm{Y}, \mathrm{y}$ & Ы, ы & Э, э & $\mathrm{E}, \mathrm{e}$ \\
\hline $\mathrm{Z}, \mathrm{z}$ & 3,3 & Ю, ю & $\begin{array}{c}\mathrm{Ju}, \mathrm{ju} \mathrm{u}^{2} \\
\mathrm{u}^{3} \\
\mathrm{iu}^{4}\end{array}$ \\
\hline Ź, ź & Зь, зь & Я, я & $\begin{array}{c}\mathrm{Ja}, \mathrm{ja}^{2} \\
\mathrm{a}^{3} \\
\mathrm{ia}^{4}\end{array}$ \\
\hline$\check{Z}, \check{z}$ & Ж, ж & & \\
\hline
\end{tabular}

1 в заимствованиях возможная запись с g, например: guzik, ganak, gont, mazgi

2 в начале слова, после гласных букв, после апострофа ('), после мягкого знака (ь)

3 после буквы Л, л

4 после других согласных букв

5 перед е, ё, я, ю, i, ь и в словах с удвоенным лл

6 мягкость обозначается над буквами: Ć, ć, ’́, ń, Ś, ś, Ź, ź

На основании белорусской латинки в Беларуси в 2007 г. разработали новый проект транслитерации белорусского алфавита, касающийся только географических названий. Важно отметить, что в этой транслитерации не используется буква $g(2)$, которая в других системах транслитерации должна была передавать редкий белорусский согласный $[\mathrm{g}]$, используемый обычно только в заимствованиях (хотя бывает, что в языковым узусе произношение унифицируется идажевзаимствованиях вместо [g] произносится согласный $[\mathrm{h}]$, как в отечественных белорусских словах). В некторых других стандартах транслитерации по примеру транслитерации с русского языка буква 2 заменялась буквай $g$, что не всеми считалось правильным. В 2012 г. новый белорусский проект транслитерации был утверждён Группой Экспертов $\mathrm{OOH}$ по географическим названиям и рекомендован белорусским и международным органам для широкого использования при транслитерации белорусских географических названий (см. Report...; Инструкиия по транслитерации...). Примеры новой транслитерации приводятся в таблице (вместе с польской транскрипцией, правила которой подаются в Постановлении Министра внутренных дел и администрачии от дня 30 мая 2005 года о транслитерации имен и фамилий лиц, придналежиющих до нащиональных и этнических меншинств, см. Rozporządzenie...). 
Белорусская транслитерация географических названий (вместе с польской транскрипцией)

\begin{tabular}{|c|c|c|c|c|}
\hline $\begin{array}{c}\text { Белорусский } \\
\text { алфавит }\end{array}$ & $\begin{array}{c}\text { Белорусская транс- } \\
\text { литерация с } 2007 \text { г., } \\
\text { рекомендована ООН } \\
\text { в } 2012 \text { г. }\end{array}$ & Примеры & $\begin{array}{c}\text { Польская } \\
\text { транскрип- } \\
\text { ция }\end{array}$ & Примеры \\
\hline A, a & $\mathrm{A}, \mathrm{a}$ & Аршанскі - Aršanski & A, a & Arszanski \\
\hline Б, б & $\mathrm{B}, \mathrm{b}$ & $\begin{array}{c}\text { Бешанковічы - } \\
\text { Biešankovičy }\end{array}$ & $\mathrm{B}, \mathrm{b}$ & Bieszankowiczy \\
\hline $\mathrm{B}$, в & $\mathrm{V}, \mathrm{v}$ & Віцебск - Viciebsk & $\mathrm{W}, \mathrm{w}$ & Wiciebsk \\
\hline$\Gamma, \Gamma$ & $\mathrm{H}, \mathrm{h}$ & $\begin{array}{c}\text { Гомель - Homieĺ, } \\
\text { Гаўя - Найja }\end{array}$ & $\mathrm{H}, \mathrm{h}^{12}$ & Homiel, Hauja \\
\hline Д, д & $\mathrm{D}, \mathrm{d}$ & Добруш - Dobruš & $\mathrm{D}, \mathrm{d}$ & Dobrusz \\
\hline \multirow[t]{2}{*}{$\mathrm{E}, \mathrm{e}$} & $\mathrm{Je}^{1}, \mathrm{je}$ & $\begin{array}{c}\text { Ельск - Jeĺsk, } \\
\text { Бабаедава - Baba- } \\
\text { jedava }\end{array}$ & $\begin{array}{c}\mathrm{Je}, \mathrm{je}^{7} \\
\mathrm{e}^{8}\end{array}$ & $\begin{array}{c}\text { Jelsk, Babaje- } \\
\text { dawa }\end{array}$ \\
\hline & $\mathrm{ie}^{2}$ & $\begin{array}{c}\text { Венцавічы — Vien- } \\
\text { cavičy }\end{array}$ & $\mathrm{ie}^{9}$ & Wiencawiczy \\
\hline \multirow[t]{2}{*}{ Ë, ë } & $\mathrm{Jo}^{1}$, jo & $\begin{array}{c}\text { Ёды - Jody, } \\
\text { Вераб'ёвічы — Vie- } \\
\text { rabjovičy }\end{array}$ & $\begin{array}{c}\mathrm{Jo}, \mathrm{jo}^{7} \\
\mathrm{o}^{8}\end{array}$ & $\begin{array}{c}\text { Jody, Wierabjo- } \\
\text { wiczy }\end{array}$ \\
\hline & $i^{2}$ & Мёры - Miory & io 9 & Miory \\
\hline Ж, ж & $\check{Z}, \check{z}$ & Жодзішкі - Žodziški & $\dot{\mathrm{Z}}, \dot{\mathrm{z}}$ & Żodziszki \\
\hline 3,3 & $\mathrm{Z}, \mathrm{z}$ & Зэльва — Zeĺva & $\mathrm{Z}, \mathrm{z}$ & Zelwa \\
\hline $\mathrm{I}, \mathrm{i}$ & $\mathrm{I}, \mathrm{i}$ & $\begin{array}{c}\text { Іванава - Ivanava, } \\
\text { Iy̆e - Iŭje }\end{array}$ & $\mathrm{I}, \mathrm{i}$ & Iwanawa, Iuje \\
\hline Й, й & $\mathrm{J}, \mathrm{j}$ & Лагойск — Lahojsk & $\mathrm{J}, \mathrm{j}$ & Łahojsk \\
\hline К, к & $\mathrm{K}, \mathrm{k}$ & Круглае - Kruhlaje & $\mathrm{K}, \mathrm{k}$ & Kruhłaje \\
\hline \multirow[t]{2}{*}{ Л, л } & $\mathrm{L}, 1$ & $\begin{array}{l}\text { Лошыца - Lošyca, } \\
\text { Любань - Liubań }\end{array}$ & $Ł, 1^{10}$ & Łoszyca, Lubań \\
\hline & $\dot{\mathrm{L}}, \mathrm{i}^{3}$ & Фаніпаль — Fanipaĺ & $\mathrm{L}, 1^{11}$ & Fanipal \\
\hline $\mathrm{M}, \mathrm{M}$ & $\mathrm{M}, \mathrm{m}$ & Магілёў - Mahilioŭ & $\mathrm{M}, \mathrm{m}$ & Mahilou \\
\hline \multirow{2}{*}{$\mathrm{H}, \mathrm{H}$} & $\mathrm{N}, \mathrm{n}$ & Нясвіж - Niasviž & $\mathrm{N}, \mathrm{n}$ & Niaswiż \\
\hline & $\hat{N}, \dot{n}^{3}$ & Любань - Liubań & & Lubań \\
\hline $\mathrm{O}, \mathrm{o}$ & $\mathrm{O}, \mathrm{o}$ & Орша - Orša & $\mathrm{O}, \mathrm{o}$ & Orsza \\
\hline$\Pi, \Pi$ & $\mathrm{P}, \mathrm{p}$ & Паставы — Pastavy & $\mathrm{P}, \mathrm{p}$ & Pastawy \\
\hline $\mathrm{P}, \mathrm{p}$ & $\mathrm{R}, \mathrm{r}$ & Рагачоў —Rahačoŭ & $\mathrm{R}, \mathrm{r}$ & Rahaczou \\
\hline \multirow[t]{2}{*}{$\mathrm{C}, \mathrm{c}$} & $\mathrm{S}, \mathrm{s}$ & $\begin{array}{c}\text { Светлагорск - Sviet- } \\
\text { lahorsk }\end{array}$ & $\mathrm{S}, \mathrm{s}$ & Swietłahorsk \\
\hline & $\dot{S}, \dot{s}^{3}$ & Беларусь - Bielaruś & & Biełaruś \\
\hline $\mathrm{T}, \mathrm{T}$ & $\mathrm{T}, \mathrm{t}$ & Талачын - Talačyn & $\mathrm{T}, \mathrm{t}$ & Tałaczyn \\
\hline $\mathrm{y}, \mathrm{y}$ & $\mathrm{U}, \mathrm{u}$ & Узда — Uzda & $\mathrm{U}, \mathrm{u}$ & Uzda \\
\hline
\end{tabular}




\begin{tabular}{|c|c|c|c|c|}
\hline y̆, y̆ & $\breve{U}, \breve{\mathrm{u}}$ & $\begin{array}{c}\text { Шаркаўшчына - } \\
\text { Šarkaŭščyna }\end{array}$ & $\mathrm{U}, \mathrm{u}$ & Szarkauszczyna \\
\hline$\Phi, \phi$ & $\mathrm{F}, \mathrm{f}$ & Фаніпаль — Fanipaĺ & $F, f$ & Fanipal \\
\hline $\mathrm{X}, \mathrm{x}$ & $\mathrm{Ch}, \mathrm{ch}$ & Хоцімск - Chocimsk & $\mathrm{Ch}, \mathrm{ch}$ & Chocimsk \\
\hline \multirow[t]{2}{*}{ Ц, ц } & $\mathrm{C}, \mathrm{c}$ & $\begin{array}{c}\text { Цёмны Лес- Ciom- } \\
\text { ny Lies }\end{array}$ & $\mathrm{C}, \mathrm{c}$ & Ciomny Les \\
\hline & $\dot{C}, \dot{c}^{3}$ & Друць - Druć & & Druć \\
\hline Ч, ч & $\check{\mathrm{C}}, \check{\mathrm{c}}$ & Чавусы - Čavusy & $\mathrm{Cz}, \mathrm{cz}$ & Czawusy \\
\hline Ш, ш & $\breve{S}, \check{s}$ & Шуміліна — Šumilina & $\mathrm{Sz}, \mathrm{sz}$ & Szumilina \\
\hline , & -4 & $\begin{array}{c}\text { Валяр'яны — Valiar- } \\
\text { jany }\end{array}$ & -4 & Walarjany \\
\hline Ы, ы & $\mathrm{Y}, \mathrm{y}$ & $\begin{array}{l}\text { Чыгірынка - Čyhi- } \\
\text { rynka }\end{array}$ & $\mathrm{Y}, \mathrm{y}$ & Czyhirynka \\
\hline $\mathrm{b}, \mathrm{b}$ & 5 & $\begin{array}{c}\text { Фаніпаль - Fanipaí, } \\
\text { Любань - Liubań, } \\
\text { Беларусь - Bielaruś, } \\
\text { Друць - Druć }\end{array}$ & 6 & $\begin{array}{l}\text { Fanipal, Lubań, } \\
\text { Biełaruś, Druć }\end{array}$ \\
\hline Э, э & E, e & Чачэрск - Čačersk & $\mathrm{E}, \mathrm{e}$ & Czaczersk \\
\hline \multirow{2}{*}{ Ю, ю } & $\mathrm{Ju}, \mathrm{ju}{ }^{1}$ & $\begin{array}{c}\text { Юхнаўка - } \\
\text { Juchnaŭka, Гаюціна } \\
\text { - Hajucina }\end{array}$ & $\begin{array}{c}\mathrm{Ju}, \mathrm{ju} \mathrm{j}^{7} \\
\mathrm{u}^{8}\end{array}$ & $\begin{array}{l}\text { Juchnauka, Ha- } \\
\text { jucina }\end{array}$ \\
\hline & $i u^{2}$ & $\begin{array}{l}\text { Цюрлі - Ciurli, } \\
\text { Любонічы — Liubo- } \\
\text { ničy }\end{array}$ & $\mathrm{iu}^{9}$ & Ciurli, Luboniczy \\
\hline \multirow[b]{2}{*}{ Я, я } & $\mathrm{Ja}, \mathrm{ja}^{1}$ & $\begin{array}{c}\text { Ямнае - Jamnaje, } \\
\text { Баяры - Bajary }\end{array}$ & $\begin{array}{c}\mathrm{Ja}, \mathrm{ja}^{7} \\
\mathrm{a}^{8}\end{array}$ & Jamnaje, Bajary \\
\hline & $\mathrm{ia}^{2}$ & $\begin{array}{c}\text { Валяр'яны - Va- } \\
\text { liarjany, Вязынка - } \\
\text { Viazynka }\end{array}$ & $\mathrm{ia}^{9}$ & $\begin{array}{l}\text { Walarjany, Wia- } \\
\text { zynka }\end{array}$ \\
\hline
\end{tabular}

1 в начале слова, после гласных букв, после апострофа ('), после мягкого знака (ь),

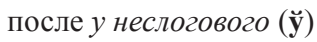

2 после согласных букв

3 когда после буквы выступает мягкий знак (ь)

4 опускается

5 мягкость обозначается над буквами: Ĺ, ĺ, Ć, ć, Ń, ń, Ś, ś, Ź, ź

${ }^{6}$ мягкость обозначается над буквами: $\mathbf{C}, \mathbf{c}, \mathbf{N}, \mathbf{n}, \mathbf{S}, \mathbf{s}, \mathbf{Z}, \mathbf{z}$

7 в начале слова, после гласных букв, после апострофа ('), после мягкого знака (ь)

8 после буквы Л, л

9 после других согласных букв

10 перед согласными буквами, перед гласными буквами $\mathbf{a}, \mathbf{0}, \mathbf{y}, \mathbf{ы}$ и в конце слова

11 перед е, ё, я, ю, i, ь и в словах с удвоенным лл

12 в заимствованиях возможная запись с $\mathbf{g}$, например: guzik, ganak, gont, mazgi

В мире существуют и другие системы транслитерации белорусских географических названий, например, транслитерация $B G N / P C G N$ с 1979 г., раз- 
работанная Советом США по географическим названиям (англ. United States Board on Geographic Names - BGN) и использующаяся в Англии (PCGN от англ. Permanent Committee on Geographical Names for British Official Use). В этой транслитерации используется основной латинский алфавит (Romanization systems... 1994: 23) (различия с другими стандартами транслитерации обозначаются в таблице толстым шрифтом).

Транслитерация географических названий BGN/PCGN з 1979 г.

\begin{tabular}{|c|c|}
\hline Белорусский алфавит & $\begin{array}{c}\text { Транслитерация } \\
\text { BGN/PCGN } 1979\end{array}$ \\
\hline $\mathrm{A}, \mathrm{a}$ & $\mathrm{A}, \mathrm{a}$ \\
\hline Б, б & $\mathrm{B}, \mathrm{b}$ \\
\hline $\mathrm{B}, \mathrm{B}$ & $\mathrm{V}, \mathrm{v}$ \\
\hline$\Gamma, \Gamma$ & $\mathrm{H}, \mathrm{h}$ \\
\hline Д, д & $\mathrm{D}, \mathrm{d}$ \\
\hline $\mathrm{E}, \mathrm{e}$ & Ye, ye \\
\hline Ë, ë & Yo, yo \\
\hline Ж, ж & Zh, zh \\
\hline 3,3 & $\mathrm{Z}, \mathrm{z}$ \\
\hline $\mathrm{I}, \mathrm{i}$ & $\mathrm{I}, \mathrm{i}$ \\
\hline Й, й & $\mathbf{Y}, \mathbf{y}$ \\
\hline K, к & $\mathrm{K}, \mathrm{k}$ \\
\hline Л, л & $\mathbf{L}, \mathbf{I}$ \\
\hline $\mathrm{M}, \mathrm{M}$ & $\mathrm{M}, \mathrm{m}$ \\
\hline $\mathrm{H}, \mathrm{H}$ & $\mathrm{N}, \mathrm{n}$ \\
\hline $\mathrm{O}, \mathrm{o}$ & $\mathrm{O}, \mathrm{o}$ \\
\hline$\Pi, \Pi$ & $\mathrm{P}, \mathrm{p}$ \\
\hline $\mathrm{P}, \mathrm{p}$ & $\mathrm{R}, \mathrm{r}$ \\
\hline $\mathrm{C}, \mathrm{c}$ & $\mathrm{S}, \mathrm{s}$ \\
\hline $\mathrm{T}, \mathrm{T}$ & $\mathrm{T}, \mathrm{t}$ \\
\hline $\mathrm{Y}, \mathrm{y}$ & $\mathrm{U}, \mathrm{u}$ \\
\hline y̆, y̆ & $\mathbf{W}, \mathbf{w}$ \\
\hline$\Phi, \phi$ & $\mathrm{F}, \mathrm{f}$ \\
\hline$X, x$ & Kh, kh \\
\hline Ц, ц & Ts, ts \\
\hline Ч, ч & Ch, ch \\
\hline Ш, ш & Sh, sh \\
\hline , & $«$ \\
\hline Ы, ы & Y, y \\
\hline $\mathbf{b}$ & ' \\
\hline Э, э & E, e \\
\hline Ю, ю & Yu, yu \\
\hline Я, я & Ya, ya \\
\hline
\end{tabular}


Также существует научная транслитерация белорусского алфавита, использующаяся в международной научной системе, например, в языкознании (различия с другими стандартами транслитерации обозначаются в таблице толстым шрифтом).

Международная научная транслитерация белорусского алфавита

\begin{tabular}{|c|c|}
\hline Белорусский алфавит & $\begin{array}{c}\text { Научная транслите- } \\
\text { рация }\end{array}$ \\
\hline $\mathrm{A}, \mathrm{a}$ & $\mathrm{A}, \mathrm{a}$ \\
\hline Б, б & $\mathrm{B}, \mathrm{b}$ \\
\hline $\mathrm{B}$, в & $\mathrm{V}, \mathrm{v}$ \\
\hline$\Gamma, \Gamma$ & $\mathrm{H}, \mathrm{h}$ \\
\hline Д, д & $\mathrm{D}, \mathrm{d}$ \\
\hline E, e & E, e \\
\hline$\ddot{\mathrm{E}}, \ddot{\mathrm{e}}$ & $\ddot{\mathbf{E}}, \ddot{\mathbf{e}}$ \\
\hline Ж, ж & $\check{\mathbf{Z}}, \check{\mathbf{z}}$ \\
\hline 3,3 & $\mathrm{Z}, \mathrm{z}$ \\
\hline $\mathrm{I}, \mathrm{i}$ & $\mathrm{I}, \mathrm{i}$ \\
\hline Й, й & $\mathbf{J}, \mathbf{j}$ \\
\hline К, К & $\mathrm{K}, \mathrm{k}$ \\
\hline Л, л & $\mathbf{L}, \mathbf{l}$ \\
\hline $\mathrm{M}, \mathrm{M}$ & $\mathrm{M}, \mathrm{m}$ \\
\hline $\mathrm{H}, \mathrm{H}$ & $\mathrm{N}, \mathrm{n}$ \\
\hline $\mathrm{O}, \mathrm{o}$ & $\mathrm{O}, \mathrm{o}$ \\
\hline П, п & $P, p$ \\
\hline $\mathrm{P}, \mathrm{p}$ & $\mathrm{R}, \mathrm{r}$ \\
\hline $\mathrm{C}, \mathrm{c}$ & $\mathrm{S}, \mathrm{s}$ \\
\hline $\mathrm{T}, \mathrm{T}$ & $\mathrm{T}, \mathrm{t}$ \\
\hline $\mathrm{y}, \mathrm{y}$ & $\mathrm{U}, \mathrm{u}$ \\
\hline$\breve{y}, \breve{y}$ & $\breve{\mathbf{U}}(\mathbf{W}), \breve{\mathbf{u}}(\mathbf{w})$ \\
\hline$\Phi, \phi$ & $F, f$ \\
\hline $\mathrm{X}, \mathrm{x}$ & $\mathbf{X}(\mathbf{C h}), \mathbf{x}(\mathbf{c h})$ \\
\hline Ц, ц & $\mathrm{C}, \mathrm{c}$ \\
\hline Ч, ч & $\check{\mathbf{C}}, \check{\mathbf{c}}$ \\
\hline Ш, ш & $\check{\mathbf{S}}, \check{\mathbf{s}}$ \\
\hline , & Опускается \\
\hline Ы ы & $\mathrm{Y}, \mathrm{y}$ \\
\hline b & 6 \\
\hline Э, Э & È, è \\
\hline Ю, ю & $\mathbf{J u}, \mathbf{j u}$ \\
\hline Я, я & $\mathbf{J a}, \mathbf{j a}$ \\
\hline
\end{tabular}


При этом надо отметить, что в библиотеках США и Англии существует своя транслитерация ALA-LC (от англ. American Library Association - Library of Congress, больше см. сайт The Library of Congress), однако в этой статье рассматриваются только европейские или международные стандарты транслитерации.

Очень распространённой международной системой транслитерации является ISO 9, разработанной в 1995 г. (ISO это название Международной организации по стандартизации, англ. The International Organization for Standardization - ISO). В этой транслитерации одной кириллической букве соответствует одна буква латинского алфавита, что позволяет производить обратную транслитерацию. В большинстве стран СНГ эта транслитерация называется ГОСТ 7.79-2000. Этот межгосударственный стандарт состоит из двух систем: системы А, с использованием диакритики, и системы Б, с использованием буквосочетаний (см. Саўка 2011: 234, Кошчанка 2015: 174-175) и представляет собой текст ISO 9:1995 «Информация и документация. Транслитерация кириллических букв латинскими. Славянские и неславянские языки». В Польше эта транслитерация называется PN-ISO 9:2000 Informacja i dokumentacja. Transliteracja znaków cyrylickich na znaki łacińskie — Języki słowiańskie i niesłowiańskie.

В стандарте транслитерации ISO 9: 1995 по примеру транслитерации с русского языка используется буква $g(2)$ вместо $h$. В более раннем варианте стандарта ISO от 1968 г. было замечание, что для белорусского и украинского языков букву г перадается как $h$ (различия с другими стандартами транслитерации обозначаются в таблице толстым шрифтом).

Транслитерация белорусского алфавита согласно стандарту ISO 9 от 1995 г.

\begin{tabular}{|c|c|}
\hline Белорусский алфавит & $\begin{array}{c}\text { Транслитерация } \\
\text { ISO 9: } 1995\end{array}$ \\
\hline $\mathrm{A}, \mathrm{a}$ & A, a \\
\hline Б, б & $\mathrm{B}, \mathrm{b}$ \\
\hline $\mathrm{B}$, в & $\mathrm{V}, \mathrm{v}$ \\
\hline$\Gamma, \Gamma$ & $\mathrm{G}, \mathrm{g}$ \\
\hline Д, д & $\mathrm{D}, \mathrm{d}$ \\
\hline E, e & $\mathbf{E}, \mathbf{e}$ \\
\hline Ë, ë & $\ddot{\mathbf{E}}, \ddot{\mathbf{e}}$ \\
\hline Ж, ж & $\check{\mathbf{Z}}, \check{\mathbf{z}}$ \\
\hline 3,3 & $\mathrm{Z}, \mathrm{z}$ \\
\hline $\mathrm{I}, \mathrm{i}$ & İ, ì \\
\hline Й, й & $\mathbf{J}, \mathbf{j}$ \\
\hline
\end{tabular}




\begin{tabular}{|c|c|}
\hline К, к & $\mathrm{K}, \mathrm{k}$ \\
\hline Л, л & $\mathrm{L}, 1$ \\
\hline $\mathrm{M}, \mathrm{M}$ & $\mathrm{M}, \mathrm{m}$ \\
\hline $\mathrm{H}, \mathrm{H}$ & $\mathrm{N}, \mathrm{n}$ \\
\hline $\mathrm{O}, \mathrm{o}$ & $\mathrm{O}, \mathrm{o}$ \\
\hline П, п & $\mathrm{P}, \mathrm{p}$ \\
\hline $\mathrm{P}, \mathrm{p}$ & $\mathrm{R}, \mathrm{r}$ \\
\hline $\mathrm{C}, \mathrm{c}$ & $\mathrm{S}, \mathrm{s}$ \\
\hline $\mathrm{T}, \mathrm{T}$ & $\mathrm{T}, \mathrm{t}$ \\
\hline $\mathrm{y}, \mathrm{y}$ & $\mathrm{U}, \mathrm{u}$ \\
\hline y̆, y̆ & $\breve{\mathbf{U}}, \breve{\mathbf{u}}$ \\
\hline$\Phi, \phi$ & $\mathrm{F}, \mathrm{f}$ \\
\hline $\mathrm{X}, \mathrm{x}$ & $\mathbf{H}, \mathbf{h}$ \\
\hline Ц, ц & $\mathrm{C}, \mathrm{c}$ \\
\hline Ч, ч & $\check{\mathbf{C}}, \check{\mathbf{c}}$ \\
\hline Ш, ш & $\check{\mathbf{S}}, \check{\mathbf{s}}$ \\
\hline , & , \\
\hline Ы ы & $\mathrm{Y}, \mathrm{y}$ \\
\hline b & 6 \\
\hline Э, э & 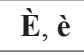 \\
\hline Ю, ю & $\hat{\mathbf{U}}, \hat{\mathbf{u}}$ \\
\hline Я, я & $\hat{\mathbf{A}}, \hat{\mathbf{a}}$ \\
\hline
\end{tabular}

Существуют также другие варианты транслитерации. Международная организация гражданской авиации (ИКАО от англ. ICAO_International Civil Aviation Organization) разработала свой очень популярный стандарт, используемый в паспортах. Отечественный вариант имени и фамилии, написанный в паспорте (например, польск. RADOSŁAW), имеет свой упрощённый эквивалент внизу страницы (RADOSLAW — без типичного для польского алфавита Ł), который прикладывается к специальному аппарату в аэропорту, чтобы проверить личные данные. Стандарт ИКАО не является транскрипцией белорусского произношения, не учитывает национальных черт белорусского ни других алфавитов (см. Кошчанка 2015: 174). В системе ИКАО используются только большие буквы английского алфавита (различия с другими стандартами транслитерации обозначаются в таблице толстым шрифтом). 
Транслитерация ИКАО

\begin{tabular}{|c|c|}
\hline $\begin{array}{c}\text { Белорусский } \\
\text { алфавит }\end{array}$ & $\begin{array}{c}\text { Транслитерация } \\
\text { ИКАО }\end{array}$ \\
\hline $\mathrm{A}, \mathrm{a}$ & A \\
\hline Б, б & B \\
\hline $\mathrm{B}, \mathrm{B}$ & V \\
\hline$\Gamma, \Gamma$ & $\mathbf{H}$ \\
\hline Д, д & D \\
\hline E, e & E \\
\hline Ë, ë & IO \\
\hline Ж, ж & $\mathbf{Z H}$ \\
\hline 3,3 & Z \\
\hline $\mathrm{I}, \mathrm{i}$ & I \\
\hline Й, й & I \\
\hline К, К & $\mathrm{K}$ \\
\hline Л, л & $\mathbf{L}$ \\
\hline M, м & M \\
\hline $\mathrm{H}, \mathrm{H}$ & $\mathrm{N}$ \\
\hline $\mathrm{O}, \mathrm{o}$ & $\mathrm{O}$ \\
\hline П, п & $\mathrm{P}$ \\
\hline $\mathrm{P}, \mathrm{p}$ & $\mathrm{R}$ \\
\hline $\mathrm{C}, \mathrm{c}$ & $\mathrm{S}$ \\
\hline $\mathrm{T}, \mathrm{T}$ & $\mathrm{T}$ \\
\hline $\mathrm{y}, \mathrm{y}$ & $\mathrm{U}$ \\
\hline y̆, y̆ & $\mathbf{U}$ \\
\hline$\Phi, \phi$ & $\mathrm{F}$ \\
\hline$X, x$ & KH \\
\hline Ц, ц & TS \\
\hline Ч, ૫ & CH \\
\hline Ш, ш & SH \\
\hline Ы ы & $\mathrm{Y}$ \\
\hline Э, э & $\mathbf{E}$ \\
\hline Ю, ю & IU \\
\hline Я, Я & IA \\
\hline
\end{tabular}

Раньше в белорусских паспортах использовали правила французской транскрипции, например, фамилия Лукашенко (белор. Лукашэнка) трансли- 
терировалось как фр. Loukachenka - белор. $y=$ фр. ou ${ }^{1}$, белор. $u=\phi p . c h$. Потом белорусское МВД начало применять новые правила на основании английского языка (больше Саўка 2011; Кошчанка 2015).

Из-за ситуации так называемого “государственного двуязычия” в Беларуси получается, что имя и фамилия белоруса, написанные на белорусском и русском языках, при транслитерации отличаются друг от друга, например белорусская фамилия Рагачоў транслитерируется как Rahachou, а русский вариант Рогачёв — как Rogachiov (пример по: А. Копач, К. Кірава (2017: 349)). По-белорусски Рагачой (рус. Рогачёв, польск. Rohaczów) обозначает также название города в Беларуси, но в этом случае используется транслитерация для географических названий, которая отличается от транслитерации фамилий, и получается форма - Rahačoй.

Количество вариантов (далеко не всех) транслитерации и транскрипции белорусского алфавита и их различия представлены в следующей таблице.

Различия между разными стандартами транслитерации и транскрипции отдельных белорусских букв

\begin{tabular}{|c|c|c|c|c|c|c|c|}
\hline 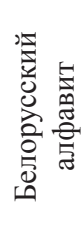 & 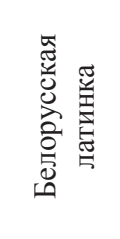 & 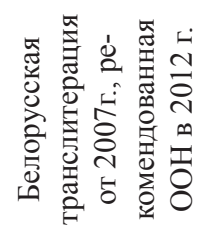 & 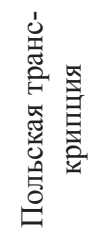 & 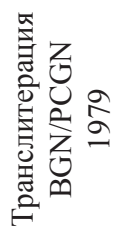 & 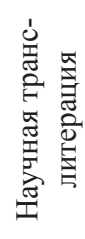 & 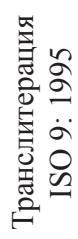 & 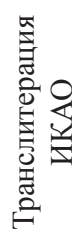 \\
\hline $\mathrm{B}$, в & $\begin{array}{c}\mathrm{V}, \mathrm{v} \\
\text { (раньше } \\
\text { W, w) }\end{array}$ & $\mathrm{V}, \mathrm{v}$ & $\mathrm{W}, \mathrm{w}$ & $\mathrm{V}, \mathrm{v}$ & $\mathrm{V}, \mathrm{v}$ & $\mathrm{V}, \mathrm{v}$ & V \\
\hline$\Gamma, \Gamma$ & $\begin{array}{c}\mathrm{H}, \mathrm{h} \\
\mathrm{G}, \mathrm{g}^{11}\end{array}$ & $\mathrm{H}, \mathrm{h}$ & $\mathrm{H}, \mathrm{h}$ & $\mathrm{H}, \mathrm{h}$ & $\mathrm{H}, \mathrm{h}$ & $\mathrm{G}, \mathrm{g}$ & $\mathrm{H}$ \\
\hline $\mathrm{E}, \mathrm{e}$ & $\begin{array}{c}\mathrm{Je}, \mathrm{je}^{6} \\
\mathrm{e}^{7} \\
\mathrm{ie}^{8}\end{array}$ & $\begin{array}{c}\mathrm{Je}, \mathrm{je}^{1} \\
\mathrm{ie}^{2}\end{array}$ & $\begin{array}{c}\mathrm{Je}, \mathrm{je}^{6} \\
\mathrm{e}^{7} \\
\mathrm{ie}^{8}\end{array}$ & Ye, ye & $\mathrm{E}, \mathrm{e}$ & $\mathrm{E}, \mathrm{e}$ & E \\
\hline Ë, ë & $\begin{array}{c}\mathrm{Jo}, \mathrm{jo}^{6} \\
\mathrm{o}^{7} \\
\mathrm{io}^{8}\end{array}$ & $\begin{array}{c}\text { Jo, jo }{ }^{1} \\
\text { io }^{2}\end{array}$ & $\begin{array}{c}\text { Jo, jo } \\
\mathrm{o}^{7} \\
\mathrm{io}^{8}\end{array}$ & Yo, yo & Ë, ë & Ë, ë & $\mathrm{IO}$ \\
\hline Ж, ж & $\begin{array}{c}\check{Z}, \check{z} \\
\text { (раньше } \\
\dot{Z}, \dot{z} \text { ) }\end{array}$ & Ž, ž & $\dot{Z}, \dot{z}$ & $\mathrm{Zh}, \mathrm{zh}$ & Ž, ž & Ž, ̌̌ & $\mathrm{ZH}$ \\
\hline $\mathrm{I}, \mathrm{i}$ & $\mathrm{I}, \mathrm{i}$ & $\mathrm{I}, \mathrm{i}$ & $\mathrm{I}, \mathrm{i}$ & $\mathrm{I}, \mathrm{i}$ & $\mathrm{I}, \mathrm{i}$ & Ì, ì & I \\
\hline Й, й & $\mathrm{J}, \mathrm{j}$ & $\mathrm{J}, \mathrm{j}$ & $\mathrm{J}, \mathrm{j}$ & $\mathrm{Y}, \mathrm{y}$ & $\mathrm{J}, \mathrm{j}$ & $\mathrm{J}, \mathrm{j}$ & I \\
\hline
\end{tabular}

${ }^{1}$ Хотя некоторые более профессиональные французские источники транслитерируют как - ̀े [Lefter 2014]. 


\begin{tabular}{|c|c|c|c|c|c|c|c|}
\hline Л, л & $\begin{array}{c}\mathrm{L}, 1^{10} \\
\llcorner, 1\end{array}$ & $\mathrm{L}, 1$ & $\begin{array}{l}\mathrm{L}, 1^{10} \\
€, 1^{9}\end{array}$ & $\mathrm{~L}, 1$ & $\mathrm{~L}, 1$ & $\mathrm{~L}, 1$ & $\mathrm{~L}$ \\
\hline y̆, y̆ & $\breve{\mathrm{U}}, \breve{\mathrm{u}}$ & $\breve{\mathrm{U}}, \breve{\mathrm{u}}$ & $\mathrm{U}, \mathrm{u}$ & $\mathrm{W}, \mathrm{w}$ & $\begin{array}{c}\breve{U}(W), \breve{u} \\
(w)\end{array}$ & $\breve{\mathrm{U}}, \breve{\mathrm{u}}$ & $\mathrm{U}$ \\
\hline $\mathrm{X}, \mathrm{x}$ & $\mathrm{Ch}, \mathrm{ch}$ & $\mathrm{Ch}, \mathrm{ch}$ & $\mathrm{Ch}, \mathrm{ch}$ & $\mathrm{Kh}, \mathrm{kh}$ & $\begin{array}{c}X(\mathrm{Ch}), x \\
\text { (ch) }\end{array}$ & $\mathrm{H}, \mathrm{h}$ & $\mathrm{KH}$ \\
\hline Ц, ц & $\mathrm{C}, \mathrm{c}$ & $\mathrm{C}, \mathrm{c}$ & $\mathrm{C}, \mathrm{c}$ & Ts, ts & $\mathrm{C}, \mathrm{c}$ & $\mathrm{C}, \mathrm{c}$ & $\mathrm{TS}$ \\
\hline Ч, ч & $\begin{array}{c}\check{C}, \check{c} \\
\text { (раньше } \\
\text { Cz, cz) }\end{array}$ & $\check{\mathrm{C}}, \check{\mathrm{c}}$ & $\mathrm{Cz}, \mathrm{cz}$ & $\mathrm{Ch}, \mathrm{ch}$ & $\check{\mathrm{C}}, \check{c}$ & $\check{\mathrm{C}}, \check{\mathrm{c}}$ & $\mathrm{CH}$ \\
\hline Ш, ш & $\begin{array}{l}\text { Š, š (рань- } \\
\text { ше Sz, sz) }\end{array}$ & Š & $\mathrm{Sz}, \mathrm{sz}$ & Sh, sh & $\breve{S}, \check{s}$ & Šs, š & $\mathrm{SH}$ \\
\hline , & -3 & $-{ }^{3}$ & $-{ }^{3}$ & " & -3 & , & -3 \\
\hline $\mathrm{b}, \mathrm{b}$ & 5 & 4 & 5 & ‘ & ‘ & ' & $-{ }^{3}$ \\
\hline Э, э & E, e & $\mathrm{E}, \mathrm{e}$ & E, e & E, e & È, è & È, è & $\mathrm{E}$ \\
\hline Ю, ю & $\begin{array}{c}\mathrm{Ju}, \mathrm{ju} \mathrm{u}^{6} \\
\mathrm{u}^{7} \\
\mathrm{iu}^{8}\end{array}$ & $\begin{array}{c}\mathrm{Ju}, \mathrm{ju}{ }^{1} \\
\mathrm{iu}^{2}\end{array}$ & $\begin{array}{c}\mathrm{Ju}, \mathrm{ju} \mathrm{u}^{6} \\
\mathrm{u}^{7} \\
\mathrm{iu}^{8}\end{array}$ & Yu, yu & $\mathrm{Ju}, \mathrm{ju}$ & $\hat{\mathrm{U}}, \hat{\mathrm{u}}$ & $\mathrm{IU}$ \\
\hline Я, я & $\begin{array}{c}\mathrm{Ja}, \mathrm{ja}^{6} \\
\mathrm{a}^{7} \\
\mathrm{ia}^{8} \\
\end{array}$ & $\begin{array}{c}\mathrm{Ja}, \mathrm{ja}^{1} \\
\mathrm{ia}^{2}\end{array}$ & $\begin{array}{c}\mathrm{Ja}, \mathrm{ja}^{6} \\
\mathrm{a}^{7} \\
\mathrm{ia}^{8} \\
\end{array}$ & Ya, ya & $\mathrm{Ja}, \mathrm{ja}$ & $\hat{\mathrm{A}}, \hat{\mathrm{a}}$ & IA \\
\hline
\end{tabular}

1 в начале слова, после гласных букв, после апострофа ('), после мягкого знака (ь),

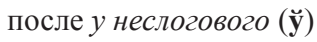

2 после согласных букв

3 опускается

4 мягкость обозначается над буквами: Ĺ, Í, Ć, ć, Ń, ń, Ś, ś, Ź, ź

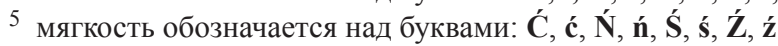

6 в начале слова, после гласных букв, после апострофа ('), после мягкого знака (ь)

7 после буквы Л, Л

8 после других согласных букв

9 перед согласными буквами, перед гласными буквами а, о, у, ы и в конце слова

10 перед е, ё, $, \mathbf{1}, \mathbf{1}, \mathbf{b}$ и в словах с удвоенным лл

11 в заимствованиях возможная запись с $\mathbf{g}$, например: guzik, ganak, gont, mazgi

В одной стране могут использоваться разные системы транслитерации (например, в Беларуси и в Польше) разными органами. Один и тот же человек в таком случае имеет как минимум две разные версии (транслитерация и транскрипция) своей фамилии в разных документах. Если все стандарты транслитерации можно было бы применить к фамилиям, тогда вариантов было бы столько же, сколько систем транслитерации, что наглядно показывает пример в таблице (формы со звёздочкой гипотетические, потому что указанные системы транслитерации относятся к географическим названиям). 
Пример разных транслитераций и транскрипций белорусской фамилии Хаўстовіч

\begin{tabular}{|c|c|c|c|c|c|c|c|}
\hline $\begin{array}{c}\text { Бело- } \\
\text { русская } \\
\text { фамилия }\end{array}$ & $\begin{array}{c}\text { Бело- } \\
\text { русская } \\
\text { латинка }\end{array}$ & $\begin{array}{c}\text { Бело- } \\
\text { русская } \\
\text { трансли- } \\
\text { терация } \\
\text { от } 2007 \text { г., } \\
\text { рекомен- } \\
\text { дованная } \\
\text { ООН в } \\
2012 \text { г. }\end{array}$ & $\begin{array}{c}\text { Польская } \\
\text { транс- } \\
\text { крипция }\end{array}$ & $\begin{array}{c}\text { Трансли- } \\
\text { терация } \\
\text { BGN/ } \\
\text { PCGN } \\
1979\end{array}$ & $\begin{array}{c}\text { Научная } \\
\text { трансли- } \\
\text { терация }\end{array}$ & $\begin{array}{c}\text { Трансли- } \\
\text { терация } \\
\text { ISO 9: } \\
1995\end{array}$ & $\begin{array}{c}\text { Трансли- } \\
\text { терация } \\
\text { ИКАО }\end{array}$ \\
\hline 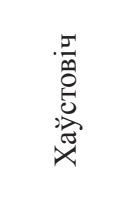 & 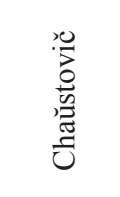 & 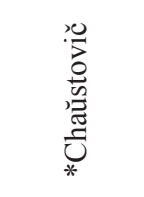 & 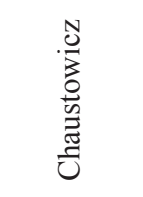 & 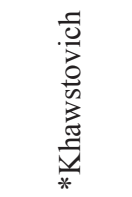 & 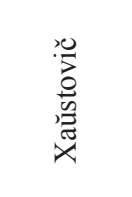 & 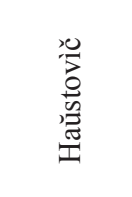 & 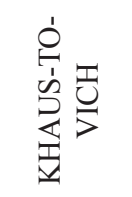 \\
\hline
\end{tabular}

Варианты, представленные во втором и третьем столбцах, являются легкими для восприятия для белорусов, четвертый столбец - для поляков, последний — для англичан. Научная транслитерация производит впечатление менее всего удобной для восприятия для обычных носителей языка.

Может показаться, что невозможно найти однозначного решения проблемы многих вариантов транслитерации, но в то же время положено хорошее начало для унификации транслитерации белорусского алфавита - это стандарт, принятый и утверждённый ООН в 2012 г. для географических названий. Может быть, придёт время, когда эта транслитерация будет применяться также в паспортах и документах других видов. Журнал “Belarusian Political Science Review” уже стал применять транслитерацию белорусского алфавита утвержденную ООН в 2012 г., для имен и фамилий своих авторов (см. сайт http://bpsreview.palityka.org). Это можно назвать ответом на всеобщее желание, которое регулярно высказывается на многих интернет-форумах и в научных трудах белорусских исследователей по транслитерации белорусского алфавита. Вопрос транслитерации вызывает в Беларуси много эмоций, в том числе в Интернете (см. тоже Сомін (в печати)). Некоторые поддерживают транслитерацию белорусского алфавита, утвержденную ООН в 2012 г., потому что она очень похожа не белорусский латинский алфавит (латинку), который передает черты белорусского языка. Другие же обращают внимание на той факт, что иностранцы, например из Западной Европы, не смогут правильно читать белорусские названия (например, названия станции метро, см. Лычавко 2012) из-за диакритики, и поэтому поддерживают стандарты транслитерации согласно английскому образцу, с использованием буквосочетаний (как, например, в транслитерации ИКАО). Это подтверждает тот факт, что выработка одного универсального для всех стандарта не является легкой задачей. Трудно соединить разные языковые традиции, особенно славянскую 
с неславянской, и тяжело ожидать, что транслитерация будет одновременно универсальной транскрипцией для иностранцев разных национальностей. Именно поэтому стоит бороться за то, чтобы была одна транслитерация, чтобы в одном тексте фамилии и географические названия не транслитерировались разным образом (см. Кошчанка 2015: 177), но при этом транскрипция должна быть в каждой стране для носителей данного языка своя.

\section{Библиография}

\section{Источники}

"Belarusian Political Science Review”, http://bpsreview.palityka.org (доступ: 21.12.2015).

ISO 91995 Information and documentation - Transliteration of Cyrillic characters into Latin Characters - Slavic and non-Slavic languages.

PN-ISO 9:2000 Informacja i dokumentacja. Transliteracja znaków cyrylickich na znaki łacińskieJęzyki stowiańskie i niestowiańskie.

Report on the Current Status of United Nations Romanization Systems for Geographical Names, http://www.eki.ee/wgrs/ (доступ: 21.12.2015).

Romanization systems and roman-script spelling conventions, 1994, prepared by United States Board on Geographic Names, Foriegn Names Comitte, United States Defense Mapping Agency, Fairfax, http://libraries.ucsd.edu/bib/fed/USBGN_romanization.pdf (доступ: 21.12.2015).

Rozporzadzenie Ministra Spraw Wewnętrznych i Administracji z dnia 30 maja 2005 r. w sprawie sposobu transliteracji imion i nazwisk osób należacych do mniejszości narodowych $i$ etnicznych zapisanych $w$ alfabecie innym niż alfabet taciński (Dz.U. Nr 102, poz. 855), http://www. mniejszosci.narodowe.mac.gov.pl/mne/prawo/zapisy-z-konstytucji-r/6448, Rozporzadzenie-Ministra-Spraw-Wewnetrznych-i-Administracji-w-sprawie-sposobu-tra.html (доступ: 21.12.2015).

The Library of Congress, http://www.loc.gov/catdir/cpso/romanization/belarusian.pdf (доступ: 21.12.2015).

Инструкция по транслитерации географических названий Республики Беларусь буквами латинского алфавита, http://www.webcitation.org/6XUwabw3U (доступ: 21.12.2015).

\section{Литература}

Lefter H.V., 2014, Pourquoi parler de Bélarus? Pourquoi ne pas parler de Biélorussie?, „Regard sur l'Est”, № 67, http://www.regard-est.com/home/breve_contenu.php?id=1528 (доступ: 21.12.2015).

Копач А., Кірава К., 2017, Стандартызацыя геаграфічных назваў Беларусі: гісторыя i сучасны стан, [w:] Białoruś w dyskursie naukowym. Lingwistyka, socjologia, politologia, red. R. Kaleta, Warszawa: Katedra Białorutenistyki UW, s. 347-367.

Кошчанка У.А., 2015, Ад „геаграфічнай” лацінкі да наџьяянальнай сістэмы раманізаџыі беларускай мовы, [в:] Зборнік матэрыялай Міжнароднай навукова-практычнай канферэнцыі «Моўныля правы і іх абарона», 28 сакавіка 2015 г. (т. 1, с. 171-178), ред. А.М. Анісім, Мінск.

Лычавко А., 2012, Какой транслит правильный?, http://news.tut.by/society/309486.html (доступ: 21.12.2015). 
Саўка 3., 2011, Беларускае ў іншамоўным: шляхі стандарызаиыі, “Acta Albaruthenica”, № 11, c. $231-238$.

Сомін А., (в печати), Праблема транслітаращьі ўласных імёнаў $і$ наіўная моўная рэфлексія (у кантэксие руска-беларускага білінгвізму).

\section{On transliteration and transcription of the Belarusian words}

Summary

The aim of the present paper is to describe the different variants of transliteration and transcription of Belarusian words, especially names and place names. In the article the most common international, Belarusian and Polish variants of the Belarusian alphabet transliteration and transcription were presented. There is need to work out one international names and place names transliteration standard.

Keywords: names, place names, transliteration, transcription, Belarusian alphabet

\section{O transliteracji i transkrypcji białoruskich wyrazów}

\section{Streszczenie}

Celem artykułu jest przedstawienie różnych wariantów transliteracji i transkrypcji wyrazów białoruskich, zwłaszcza nazwisk i nazw geograficznych. W tekście zaprezentowano najpopularniejsze międzynarodowe, białoruskie i polskie systemy transliteracji i transkrypcji alfabetu białoruskiego oraz podkreślono ogromną potrzebę wypracowania jednego międzynarodowego standardu transliteracji, odnoszącego się zarówno do nazwisk, jak i nazw geograficznych.

Stowa kluczowe: nazwiska, nazwy geograficzne, transliteracja, transkrypcja, alfabet białoruski 